\title{
A PERCEPÇÃO SOBRE CIÊNCIA TECNOLOGIA E SOCIEDADE (CTS) DE ALUNOS DO CURSO DE LICENCIATURA EM EDUCAÇÃO DO CAMPO
}

\author{
Fernanda Welter ADAMS 1 \\ Simara Maria Tavares NUNES ${ }^{2}$
}

\begin{abstract}
Resumo
A metodologia de ensino ainda se pauta na transmissão/recepção de conteúdos, sendo necessário se modificar a forma de ensinar Ciências. O presente artigo relata a visão de alunos de um Curso de Licenciatura em Educação do Campo/Habilitação em Ciências da Natureza, antes de cursarem uma disciplina que discute o ensino a partir da abordagem CTS. Esta é uma pesquisa de cunho qualitativo tendo questionários como instrumento de coleta de dados, que mostraram que em alguns momentos os licenciandos demostram uma visão romantizada das Ciências, mas acreditando que essa não é uma verdade absoluta, sendo importante para a formação de cidadãos críticos e conscientes. Portanto, este artigo permite demonstrar a necessidade de se garantir a discussão do ensino CTS aos licenciandos em formação inicial. Desta forma, a partir da vivência dessa discussão crítica, espera-se modificá-los na sua futura prática pedagógica em Ensino de Ciências.
\end{abstract}

Palavras-chave: CTS. Ensino de Ciências. Formação Inicial. Licenciandos

\footnotetext{
${ }^{1}$ Licenciada em Química e Pedagogia com mestrado em Educação. Secretaria Municipal de Educação de Catalão. ORCID: 0000-0003-4935-5198.

E-mail: adamswfernanda@gmail.com.

${ }^{2}$ Licenciada e Bacharel em Química, Mestre e Doutora em Ciências. Universidade Federal de Catalão. ORCID: 00000002-7196-4398.

E-mail:simaramn@gmail.com.
} 
Fernanda Welter ADAMS

Simara Maria Tavares NUNES

\begin{abstract}
Traditionally, the teaching methodology of science and technology is based on the transmission and reception of content and it needs to change. Therefore, this article reports the perceptions of undergraduate students of a licensing course of Countryside Education/qualification in Natural Sciences. The subjects were interviewed before taking a discipline that discusses teaching from the STS approach. A qualitative research method is applied in this study. We developed questionnaires as instrument of data collection. The results identified that the undergraduates are likely to have a romanticized view of Sciences, but they are aware that it is not an absolute truth, which this is very important for the formation of critical citizens. Therefore, this article argues about the importance of discussing STS teaching with undergraduate students in initial training. By the critical discussion approach, we hope that their pedagogical practice in science teaching will change.
\end{abstract}

Keywords: STS. Science teaching. Initial training. Undergraduates. 


\title{
LA PERCEPCIÓN SOBRE CIENCIA, TECNOLOGÍA Y SOCIEDAD (CTS) DE LOS ALUMNOS DEL CURSO DE LICENCIAMIENTO EN EDUCACIÓN CAMPESINA Y RURAL
}

\author{
Fernanda Welter ADAMS \\ Simara Maria Tavares NUNES
}

\begin{abstract}
Resumen
La metodología de enseñanza sigue basándose en la transmisión y recepción de contenidos, siendo necesario modificar la forma de enseñar las Ciencias. Este artículo relata la visión de los estudiantes de un Curso de Licenciatura en Educación del Campo/Habilitación en Ciencias de la Naturaleza. Esta investigación cualitativa utilizó cuestionarios para recoger datos de los alumnos antes de ellos tomaren la disciplina que trató la enseñanza desde el enfoque CTS. El análisis mostró que estos estudiantes tenían una visión romantizada de las Ciencias; más creyendo que esta no es una verdad absoluta; siendo importante para la formación de ciudadanos críticos y conscientes. En conclusión, este artículo demuestra la necesidad de garantizar la discusión de la enseñanza CTS a los Licenciados en formación inicial. Se espera que mediante la vivencia de la discusión crítica de la enseñanza de las Ciencias; las prácticas pedagógicas de esos estudiantes sean modificadas.
\end{abstract}

Palabras clave: CTS. Enseñanza de las ciencias. Formación inicial. Titulación, Licenciatura. 


\section{Introdução}

Atualmente constatamos que a Ciência e a Tecnologia evoluem em um ritmo bastante acelerado, influenciando cada vez mais a vida dos cidadãos. Dessa forma, a expectativa é de que as futuras gerações estejam sujeitas a mudanças significativas, com elevado impacto social, econômico e ambiental, sendo necessária uma educação que lhes possibilite a compreensão e adaptação a essa mudança (SÁ, 2002). Segundo Silva e Amaral (2013) esse processo de compreensão e adaptação, sobretudo social, demanda um novo desafio de formação dos indivíduos, especificamente no âmbito do Ensino de Ciências: articular questões relevantes no contexto social a aspectos inerentes ao desenvolvimento científico e tecnológico.

Relacionado a isto, uma das tarefas mais difíceis para o professor é romper a barreira do ensino tradicional que persiste nas práticas docentes na escola, buscando utilizar métodos inovadores que despertem a curiosidade do aluno, desenvolvendo neste o senso crítico (NUNES et. al., 2009). Acredita-se que a abordagem CTS de ensino representa um destes caminhos na direção da inovação do Ensino de Ciências. Nessa perspectiva Adams et al (2016) ao desenvolver uma aula que promoveu a contextualização do conhecimento Químico por meio da abordagem Ciência, Tecnologia e Sociedade (CTS), pôde observar que esta contextualização do conteúdo possibilitou que os alunos vivenciassem uma aula diferenciada, em que foram motivados a buscar de forma autônoma o seu conhecimento e desta forma se familiarizaram com o mesmo, tornando-se autônomos e capazes de alcançar um aprendizado efetivo. De acordo com Santos (2007), a contextualização no currículo poderá ser constituída por meio da abordagem de temas sociais e situações reais de forma dinamicamente articulada que possibilite a discussão, transversalmente aos conteúdos e aos conceitos científicos, de aspectos sociocientíficos concernentes a questões ambientais, econômicas, sociais, políticas, culturais e éticas.

O ensino CTS permite esta interação do educando com o mundo, pois propicia a alfabetização científica, despertando o senso crítico e reflexivo do aluno (ADAMS et. al., 2016). Com relação a alfabetização científica, Chassot (2003) salienta que essa se trata de um conjunto de conhecimentos que facilitariam aos homens e mulheres fazerem uma leitura do mundo em que vivem. Discutindo as vantagens do ensino CTS na formação do aluno, Hofstein, Aikenhead e Riquarts (1988) afirmam que este pode ser caracterizado como o ensino do conteúdo de ciências no contexto autêntico do seu meio tecnológico e social, no qual os estudantes integram o conhecimento científico com a tecnologia e o mundo social de suas experiências do dia-a-dia. A proposta curricular CTS corresponde, portanto, a uma integração entre educação científica, tecnológica e social, em que os 
conteúdos científicos e tecnológicos são estudados juntamente com a discussão de seus aspectos históricos, éticos, políticos e socioeconômicos (LÓPEZ e CEREZO, 1996).

Outros autores como Aikenhead (1994) são de opinião que os benefícios da introdução da abordagem CTS nas aulas de Ciências são reais e consistentes, porque entre outras coisas, aumentam a interação científica dos alunos, promovem o seu interesse pela Ciência, ajudam os alunos a melhorar o espírito crítico, o pensamento lógico e a tomada de decisão. Tudo isso nos leva a crer que promover a vivência dos educandos com aulas dentro da abordagem CTS promove o desenvolvimento cognitivo dos mesmos e os primórdios de uma formação cidadã, que é tão almejada na atualidade; isso, claro, se o professor promover oportunidades para que esse ensino ocorra em sala de aula.

Com relação à prática de professores e a abordagem citada, Vieira e Martins (2004) afirmam que esta normalmente não está integrada na abordagem CTS nem promove o pensamento crítico dos alunos, porque se centra habitualmente na transmissão de conhecimentos. Um estudo realizado por estes investigadores orientado para a formação de professores de acordo com a abordagem CTS mostrou que no final da formação os professores reconstruíram as concepções que tinham inicialmente sobre a Ciência neutra, dogmática e linear - sobre a Tecnologia e sobre a Sociedade; os dados mostraram ainda que o programa de formação induziu uma prática pedagógica de orientação CTS. Sendo assim, acredita-se que seja necessário garantir que os cursos de formação de professores de Ciências (Biologia, Física e Química) discutam o ensino a partir da abordagem CTS. Mortimer e Santos (1999) corroboram com essa afirmação quando dizem que a existência de um enfoque CTS nas estruturas curriculares das faculdades formadoras destes profissionais torna-se importante e urgente, uma vez que tal abordagem diferencia e promove qualidade ao processo de ensino-aprendizagem.

Nesse sentido, o presente artigo pretende relatar a visão sobre Ciência, Tecnologia e Sociedade (CTS) de alunos do Curso de Licenciatura em Educação do Campo/Habilitação em Ciências da Natureza da Universidade Federal de Goiás/Regional Catalão (EDUCampo/UFG/RC) antes de cursarem uma disciplina que busca discutir a perspectiva de ensino a partir da abordagem CTS. Tais alunos já haviam cursado outras disciplinas que abordaram o estudo teórico da abordagem CTS (Introdução às Ciências da Natureza e Educação do Campo e Laboratório de Ensino de Ciências da Natureza 1) e já haviam tido aulas de Química baseadas na perspectiva CTS de Ensino (Química 1, 2 e 3). 


\section{Metodologia}

A disciplina Ciência, Tecnologia e Sociedade (CTS) é ministrada no $6^{\circ}$ semestre do Curso de Licenciatura em Educação do Campo da Universidade Federal de Goiás/Regional Catalão (EDUCampo/UFG/RC). Ela ocorre no currículo depois que o aluno já cursou algumas disciplinas Pedagógicas que trabalham o conhecimento teórico da abordagem CTS como Introdução às Ciências da Natureza e Educação do Campo (1 $1^{\circ}$ Período) e Laboratório de Ensino de Ciências da Natureza 1 ( $4^{\circ}$ Período). Neste período (6 ${ }^{\mathrm{a}}$ Período), os alunos também já cursaram três disciplinas de Química, três de Física e três de Biologia. As três disciplinas de Química são ministradas na perspectiva de ensino CTS, propiciando assim aos licenciandos a vivência da abordagem. Há que se frisar, ainda, que nesta disciplina os licenciandos têm a oportunidade de vivenciar ao final a primeira experiência de elaboração de aulas contextualizadas na abordagem CTS de Ensino.

No primeiro dia da disciplina Ciência, Tecnologia e Sociedade aplicou-se um questionário aos licenciandos da primeira turma do curso com o objetivo de se avaliar a visão dos mesmos em relação à Ciência, à Tecnologia e à Sociedade. Portanto, antes das discussões críticas com a primeira turma de alunos do Curso (ingresso em 2014/1) buscou-se conhecer um pouco das percepções dos discentes para que se direcionasse melhor as discussões durante a disciplina. Essa disciplina almeja discutir a tríade Ciência, Tecnologia e Sociedade à luz da contribuição da Química, Física e Biologia; as revoluções das Ciências e os seus desdobramentos na compreensão do homem, da sociedade e da educação; a prática de Ensino de Ciências no contexto da formação do cidadão; a importância da Educação Científica na sociedade atual, bem como a Alfabetização científica e formação de cidadãos. Ao final, das discussões os licenciandos são orientados a elaborar uma sequência didática na abordagem de ensino CTS.

Para se avaliar a visão dos alunos sobre a tríade Ciência, Tecnologia e Sociedade (CTS), aplicaram-se então questionários no primeiro dia da disciplina. Estes foram em seguida analisados para se avaliar a visão dos licenciandos sobre a tríade. Toda essa análise foi desenvolvida dentro de uma pesquisa qualitativa (LUDKE e ANDRÉ, 1986). Na pesquisa qualitativa o principal interesse é avaliar o meio, o comportamento dos alunos e suas opiniões sobre a temática abordada e se os mesmos construíram conhecimentos. Martins (2004) afirma que a pesquisa qualitativa é importante porque permite coletar evidências a respeito do tema abordado de maneira criadora e intuitiva, visto que há uma proximidade entre pesquisador e pesquisado, possibilitando a compreensão de crenças, tradições, em um máximo entrelaçar com o objeto em estudo. Segundo Zago (2003) uma pesquisa na perspectiva qualitativa deve permitir a compreensão da realidade homogênea do ambiente de 
estudo; condição que se articula à percepção apontada anteriormente sobre pesquisador e participante da pesquisa.

Como dito anteriormente fez-se uso de questionários como instrumento de coleta de dados, sendo estes aplicados a 12 (doze) alunos da primeira turma EDUCampo/UFG/RC (92\% dos participantes do sexo feminino e 8\% do sexo masculino, com idades entre 30 e 69 anos). O questionário era constituído de 7 (sete) questões abertas referentes a conceitos como Ciência, Tecnologia e Sociedade; a visão dos discentes sobre os cientistas; sobre o desenvolvimento da Ciência e da Tecnologia; sobre a relação entre Ciência, Tecnologia e Sociedade; a importância da Ciência para a formação dos sujeitos e sobre a importância da discussão desta tríade (CTS) em sala de aula. Marconi e Lakatos (2010, p. 184) definem os questionários como "um instrumento de coleta de dados constituído por uma série ordenada de perguntas, que devem ser respondidas por escrito e sem a presença do entrevistador”.

Para Gil (1999, p. 128) os questionários correspondem a uma técnica de investigação que por meio de um número mais ou menos elevado de questões escritas visa "ao conhecimento de opiniões, crenças, sentimentos, interesses, expectativas, situações vivenciadas, etc.”. Como vantagens do uso de questionários para a coleta de dados, temos:

a) Implica menores gastos com pessoal, posto que o questionário não exige o treinamento dos pesquisadores; b) Garante o anonimato das respostas; c) Permite que as pessoas o respondam no momento em que julgarem mais conveniente; d) Não expõe os pesquisadores à influência das opiniões e do aspecto pessoal do entrevistado (GIL, 1999, p. 128).

Para garantir o anonimato dos participantes foram criados códigos para a sua identificação; a seleção destes seguiram os seguintes critérios: adotou-se a letra L para os licenciandos seguido dos números “1”, “2”, etc. o que resultou na sequência de L1 à L12. Para determinar a sequência optou-se por utilizar a ordem em que os questionários foram recebidos e tabulados. Após o movimento de tabulação de todos os dados, iniciou-se o processo de apropriação das informações. Para tanto, foi realizada uma leitura sistematizada e tendo em vista a Análise Textual Discursiva organizaram-se estas informações em categorias e realizou-se a interpretação dos sentidos à luz do referencial teórico adotado.

Moraes e Galiazzi (2006, p. 7) definem esta abordagem como "uma metodologia de análise de dados e informações de natureza qualitativa com a finalidade de produzir novas compreensões sobre os fenômenos e discursos”, sendo um processo auto-organizado constituído de três etapas: unitarização, categorização e comunicação. 
A análise Textual Discursiva se inicia pelo processo de unitarização, que compreende a desmontagem dos textos. Estes são examinados detalhadamente e fragmentados em unidades de análise, também denominadas unidades de significado (MORAES; GALIAZZI, 2007). Em seguida se inicia o processo de categorização que se trata de um processo cíclico, pois por meio do retorno aos mesmos elementos é possível aperfeiçoar e delimitar as categorias com maior rigor e precisão. O terceiro estágio do ciclo de análise é a comunicação das novas compreensões atingidas ao longo dos dois estágios anteriores. É um exercício de explicitação das novas estruturas emergentes da análise. Concretiza-se em forma de metatextos em que os novos insights atingidos são expressos em forma de linguagem e em profundidade e detalhes (MORAES; GALIAZZI, 2007).

Dessa forma, foram criadas três categorias pelo método indutivo, no qual as categorias são criadas à posterior, após as análises. Segundo Moraes e Galiazzi (2016) o método indutivo implica produzir as categorias a partir das unidades de análise construídas a partir do “corpus”. Por um processo de comparar e contrastar constantes entre as unidades de análise, o pesquisador vai organizando conjuntos de elementos semelhantes, geralmente com base em seu conhecimento tácito, conforme descrevem Lincoln e Guba (1985). Esse é um processo indutivo, de caminhar do particular ao geral, resultando no que se denomina as categorias emergentes (MORAES; GALIAZZI, 2016). Aquele no qual o pesquisador reúne informações textuais - unidades de significado - baseado em semelhanças empíricas entre estas que o leva à generalização e ao estabelecimento de uma categoria.

Assim, foram criadas as seguintes categorias: (1) Visão de Ciência dos alunos do Curso de Licenciatura em Educação do Campo da UFG/RC; (2) Relação Ciência e Sociedade na visão de licenciandos do Curso de Licenciatura em Educação do Campo/Habilitação em Ciências da Natureza; (3) Ciência e Tecnologia: a importância para a formação do cidadão. Estas serão discutidas a seguir.

\section{Resultados e Discussões}

Muito se discute da necessidade de a escola formar para a cidadania, fazendo uso dos diversos recursos didáticos e metodologias de ensino disponíveis, mas pouco se vê isso acontecendo. Portanto, se faz necessário provocar mudanças nas práticas, inserindo novos recursos didáticos e metodologias, como a abordagem de ensino que relaciona Ciência, Tecnologia e Sociedade (CTS). Santos e Schnetzler (2000) ressaltam que enquanto o ensino clássico se caracteriza pela organização curricular centrada no conteúdo específico das Ciências, o ensino CTS se caracteriza por uma 
organização conceitual centrada em temas sociais. Neste tocante, Linsingen (2007) afirma que os currículos escolares, ao serem organizados sob a forma de temas sociais, devem conter estratégias de ensino centradas na participação efetiva dos alunos, onde os temas são explorados com caráter multidisciplinar e os conceitos são abordados em uma perspectiva relacional, evidenciando as diferentes dimensões do conhecimento estudado.

Nesse sentido, este trabalho relata a percepção sobre Ciência de licenciandos da $1^{\circ}$ Turma do Curso de Licenciatura em Educação do Campo/Habilitação em Ciências da Natureza da Universidade Federal de Goiás / Regional Catalão (EDUCampo/UFG/RC) frente à tríade CTS. A seguir, refletiremos a oportunidade de terem uma disciplina com tal discussão permitiu que os discentes desenvolvessem uma visão de ensino diferenciada, de forma que levem em consideração o desenvolvimento de práticas, a partir dessa abordagem, quando forem professores. Como dito anteriormente, durante o curso, os licenciandos têm a oportunidade de discutir a abordagem CTS e, ainda, de experienciar tal abordagem em disciplinas do curso, como no caso das disciplinas de Química e em uma disciplina especifica (CTS), na qual além de discutir teoricamente a abordagem, tem a oportunidade de vivenciar a elaboração de uma sequência didática dentro da abordagem. Assim, para se analisar a visão dos alunos sobre a tríade CTS foram aplicados questionários aos alunos da primeira turma do curso. Após o tratamento dos dados, realizado a partir da Análise Textual Discursiva foram criadas três categorias, discutidas a seguir.

\section{Visão de Ciência dos alunos do Curso de Licenciatura em Educação do Campo/UFG/RC}

Em alguns dicionários podemos encontrar definições de Ciência e de cientista, sendo Ciência colocada como conhecimento profundo sobre algo ou alguma coisa e cientista aquele que faz, produz, se dedica à Ciência. Segundo Kosminsky e Giordan (2002, p. 11) as definições estão comprometidas “com as práticas e valores de uma cultura representativa de sua respectiva área de conhecimento”. Assim como o dicionário possui definições, em analogia, as pessoas também carregam concepções, e as mesmas são permeadas de suas leituras, imagens e percepções oriundas da sua história de formação, da sua cultura e seus referenciais (VIGOTSKI, 2001). Segundo Chassot (2015, p. 35):

A ciência, mesmo que às vezes permite que tal se infira, não está sendo considerada como uma entidade que possa ser pensada como um ente individual. Logo, dentro dessa perspectiva, não cabe considerar, por exemplo, a ciência como sendo boa ou sendo má. A ciência é um construto 
humano - logo falível e não detentora de dogmas, mas de verdades transitórias - e, assim, resposta às realizações dos homens e das mulheres.

Outro autor que define Ciência é Sirgado (2000, p. 49), tendo suas bases no materialismo histórico-dialético:

Um produto da atividade humana, não um dado puro da razão nem a simples expressão da realidade natural das coisas. Como qualquer produção humana, a ciência está ligada às condições da sua produção. Em termos gerais, pode-se dizer que a ciência é a natureza pensada pelo homem que, dessa maneira, passa a integrar a história humana na forma de ciência da natureza. A natureza em si mesma não tem história (SIRGADO, 2000, p. 49).

Tendo em mente que é primordial que os futuros professores da área de Ciências da Natureza (Biologia, Física e Química) tenham uma visão integral em relação à Ciência e ao indivíduo que “faz ciência”, perguntou-se aos licenciandos qual sua visão a respeito dos cientistas. De modo a analisar como estes enxergam o cientista e a atividade cientifica:

Excerto 1 - Cientista é aquela pessoa que busca através de pesquisas provar sua teoria sobre determinada coisa (L1).

Excerto 2 - Uma pessoa extraordinária e sensata, aquele indivíduo que age sob pressão e sabe muito bem assimilar o físico e o mental (L4).

Excerto 3 - Um cientista que contribuiria para o bem estar da população e que saiba direcionar sua pesquisa em função das pessoas. A função do cientista é realizar pesquisas em função dos seres humanos.

Por meio destes excertos e de outras respostas dos demais licenciandos, podemos observar que os licenciandos tem uma visão romantizada do cientista, ingênua, de um ser superdotado, neutro, estudioso e que só trabalha em prol do bem da humanidade, que age de forma sensata, mesmo sob pressão. Este resultado é parecido com o que Reis e Galvão (2006) encontraram com alunos da educação básica de Portugal, que descrevem os cientistas como pessoas dedicadas à evolução do conhecimento e à melhoria das condições de vida da população.

Da mesma forma, em pesquisa realizada por Duarte e Parente (2006) alunos recém-ingressantes na graduação afirmaram que os cientistas trabalham para o bem da humanidade e a ciência trabalha para a melhoria de vida da sociedade. Reis e Galvão (2006) acreditam, ainda, que a falta de conhecimentos processuais e epistemológicos da ciência se devem a estereótipos veiculados pela mídia e à falta de reflexão sobre esses aspectos em sala de aula, tal como Freire (1996) sinalizou. Isso não significa negar a possibilidade de aplicação da Ciência para benefício da sociedade, mas é preciso deixar claro que pode haver outras finalidades mais complexas. Mas, na visão dos licenciandos EDUCampo/UFG/RC, os cientistas buscam o conhecimento para o bem da humanidade, não se atentando para as contradições da Ciência, que também tem suas descobertas, por exemplo, 
empregadas para o campo bélico. Agrava-se o fato de que esta não é uma visão de alunos ingressantes, mas de alunos só sexto período do curso, quase em vias de integralização curricular.

Outra questão feita para os futuros professores foi quanto a sua visão com relação à Ciência:

Excerto 4 - [...] informações fundamentais para a sociedade. Sim, a busca de conhecimentos e investigação é fundamental para uma sociedade (L2).

A fala de L2 representa a visão de parte dos licenciandos que acreditam que a função da Ciência é garantir o bem estar da sociedade. Reis e Galvão (2006) identificaram concepções de estudantes parecidas com estas, para os quais a principal finalidade da Ciência seria a resolução dos problemas para o bem-estar da humanidade, como se a ciência estivesse sempre alheia a interesses pessoais ou de grupos dominantes. Igualmente, os alunos pesquisados por Avanzi et. al. (2011) também citaram a Ciência com função de beneficiar a sociedade. Os autores destacaram que, como a mídia realiza divulgação de pesquisas científicas diversas, que visam à melhoria da qualidade de vida das pessoas, isso pode reforçar esta imagem da Ciência (TOMAZI e.t al., 2009).

Neste sentido, Fensham (1999) afirma que grande parte dos conhecimentos científicos adquiridos pela população adulta foram por influência das diversas mídias, reforçando a compreensão de que há um poder, não só de divulgação, mas também de sugestão nos conteúdos que são veiculados. Por exemplo, ao analisarem o programa televisivo Repórter Brasil veiculado pela TV Brasil, Reznik et. al. (2014) identificaram que, dentre as 37 (trinta e sete) reportagens sobre as consequências das pesquisas científicas, 32 (trinta e dois) fizeram referência às promessas e benefícios da Ciência e apenas três matérias abordaram danos ou riscos potenciais das pesquisas. Mesmo que os textos sejam de boa qualidade e que façam adequadamente a contextualização (citada pelos autores) ainda exibem de modo desigual as possíveis consequências da Ciência, apresentando, portanto, uma visão sempre otimista da mesma. Outros licenciandos, ao serem questionados sobre a mesma temática, deram margem a outras interpretações:

Excerto 5 - A ciência é um conjunto de conhecimentos empíricos e teóricos, onde a origem da ciência moderna se tornou possível através do uso de muitos métodos [...] a observação e explicação e os experimentos (L4).

Excerto 6 - Porém não há uma verdade absoluta. Até que se prove o contrário. A ciência altera-se ao longo do tempo (L1).

Os excertos supracitados já fazem referência a outra concepção dos licenciandos, que têm uma ideia de que a Ciência se altera, se renova através de pesquisas, de que não é algo pronto e acabado, observa-se anda a percepção dos licenciandos de que a Ciência é uma criação humana para compreender a natureza e, assim, por ser um construto humano, pode ser falho. Destaca-se que as concepções de ciência e de cientista foram trabalhadas com estes sujeitos desde o primeiro período a 
partir da disciplina de Introdução às Ciências da Natureza e Educação do Campo. Portanto, os licenciandos já têm uma noção de que a Ciência está em constante movimento e alteração.

Acreditamos ser de fundamental importância que os futuros professores tenham uma visão crítica frente a conceitos básicos com os quais vão trabalhar. Conhecer o papel da Ciência é importante para que se possa analisar criticamente as informações que recebemos e as decisões políticas, econômicas e socioambientais que regem a nossa sociedade e que atingem diretamente todos os cidadãos. Consideramos que a escola, bem como as Instituições de Ensino Superior, tem um papel fundamental nesse processo.

Segundo Gatti, Nardi e Silva (2010), alguns autores têm afirmado que a concepção de Ciência do professor pode interferir na forma como este ensina. Dessa forma, uma visão positivista sobre a construção do conhecimento científico, por exemplo, implicaria a adoção de metodologias de ensino baseadas na transmissão e recepção passiva de conhecimentos considerados como verdadeiros e imutáveis, dificultando aceitação de novas metodologias (HEWSON et. al., 1999 a-b, apud GATTI; NARDI; SILVA, 2010). Percebe-se que esta não é a visão dos licenciandos pesquisados, que percebem a Ciência em constante evolução. As concepções dos professores sobre as interações CTS devem ser conhecidas, uma vez que tais concepções dos professores influenciam não só o que ensinam, mas também o como ensinam. Além disso, como salienta Acevedo-Díaz (2001, apud MAGALHÃES e TENREIRO-VIEIRA, 2006), as concepções dos professores devem ser conhecidas porque, implícita ou explicitamente, são transmitidas na sala de aula.

E como Gil-Perez et al. (2001) acreditamos que seja extremamente importante eliminar a ideia de que fazer Ciência é uma tarefa para gênios, pessoas de capacidade acima da média, realizada por pessoas solitárias, ingênuas, alheias à realidade e à sociedade trazendo para a discussão todos os aspectos que envolvam o cientista e a ciência, como por exemplo, os aspectos históricos, sociais, culturais e políticos presentes em seu contexto.

Chassot (2003) também enfatiza que não devemos apresentar para nossos alunos a imagem de uma ciência neutra, centrada numa verdade objetiva e de construção progressiva da sociedade em torno dessa verdade, pois na Ciência não existe uma verdade imutável, mas sim algumas verdades que são transitórias e que inclusive de tempos em tempos se transformam.

Portanto, acreditamos que preparar os futuros professores e também os professores em atividade para que discutam o papel das ciências na construção do conhecimento, promovendo assim aos alunos uma formação pautada na reflexão da sociedade, ou seja, uma formação para a cidadania é uma das funções dos cursos de formação de professores de Ciências da Natureza. 


\section{Relação Ciência, Tecnologia e Sociedade na visão de licenciandos do Curso de Licenciatura em Educação do Campo/Habilitação em Ciências da Natureza/UFG/RC}

O papel transformador do progresso científico-tecnológico sobre a sociedade é considerado um dos aspectos mais marcantes das sociedades atuais (CACHAPUZ, 2011). Essas transformações afetam todos os setores da sociedade e todas as áreas do conhecimento “[...] é na tensão entre as possibilidades e os riscos criados pelo conhecimento das Ciências Naturais e sua tecnologia que vivemos no mundo contemporâneo” (DELIZOICOV, ANGOTTI, PERNAMBUCO, 2009, p. 127).

Sendo assim, é de grande importância se discutir estas relações também nos cursos de formação de professores, de forma a garantir que estes exercitem debates críticos acerca desta temática na Educação Básica em sua futura atuação profissional docente. Neste panorama, Santos e Auler (2011) ressaltam que o Ensino das Ciências, para todos os níveis de escolaridade deve preocupar-se com outras dimensões do saber para além dos conteúdos disciplinares específicos; para isso é necessário conhecer os contextos nos quais os problemas ocorrem, as variáveis que os afetam e os valores que subjazem à procura de soluções, sendo tais discussões de enorme importância. Dessa forma, questionou-se os licenciandos EDUCampo/UFG/RC sobre sua opinião sobre a relação entre Ciência e Sociedade.

Excerto 7 - É impossível pensar a sociedade sem a ciência. Uma está integrada à outra. Pensando assim, a ciência interfere e muito na construção dos valores da sociedade (L1).

Excerto 8 - Está sempre presente em nossa sociedade através de produtos consumidos, em medicamentos e outros. Sim, a ciência reflete pelo fato de que depende da tecnologia atual e cultural o conhecimento cotidiano (L2).

Excerto 9 - Ela se relaciona com a sociedade e seus conhecimentos contribuem para a mudança da sociedade (L11).

Analisando-se os excertos acima e demais respostas dos licenciandos, percebe-se que todos veem relação entre a Ciência e a Sociedade e a inter-relação entre ambas, citando ligações diversificadas, desde uma visão mais ingênua de que a Ciência está em tudo e de que contribui com nosso cotidiano, passando pela consideração da importância do conhecimento científico para a formação do cidadão, até a visão de que a ciência interfere na construção de valores da sociedade. O que contrasta com o discutido na categoria anterior, onde prevaleceu uma visão ingênua e romantizada da Ciência. Das respostas analisadas, pode-se perceber que os licenciandos percebem a influência que a Ciência e a Tecnologia exercem na sociedade. Porém, a visão que tem da tecnologia também remete a categoria anterior, onde apenas os benefícios da mesma são citados, sem que se reflita sobre os impactos negativos de uma forma mais aprofundada. Algumas das 
respostas dos licenciandos refletem essa visão, indicando também que percebem muito a tecnologia nos meios de comunicação e na atuação docente:

Excerto 10 - Hoje praticamente em tudo que comunicamos há uma tecnologia envolvida. Os meios de produção buscam alternativas mais avançadas a cada dia que passa, visando atender as demandas da população (L1).

Excerto 11 - A tecnologia se envolve com a informação, com computadores $e$ celulares, são meios que facilitam a vida do professor. Por exemplo, o sitio é uma tecnologia que ajuda muito o professor e o aluno (L5).

Tais resultados permitem concluir que é de grande importância a discussão do enfoque CTS na formação de professores, pois além de garantir uma visão científica do que é a ciência e a tecnologia, permite também que os futuros professores levem essa discussão para a sala de aula, promovendo então a superação do ensino tradicional pautado na transmissão recepção dos conhecimentos. Teixeira (2003, p.182), corrobora com essa afirmação dizendo que "o movimento CTS procura colocar o ensino de ciências numa perspectiva diferenciada, abandonando posturas arcaicas que afastam o ensino dos problemas sociais”. E Auler (1998) tratando especificamente do ensino de Ciências, destaca que o enfoque educacional CTS objetiva: promover os interesses dos estudantes em relacionar a ciência com as aplicações tecnológicas e os fenômenos da vida cotidiana e abordar os estudos daqueles fatos e aplicações científicas que tenham maior relevância social; abordar as implicações sociais e éticas relacionadas ao uso da tecnologia e adquirir uma compreensão da natureza da ciência e do trabalho científico.

Dessa forma, percebe-se a importância de uma visão crítica da relação Ciência e Tecnologia entre os futuros professores, de forma que estes possam trabalhar de forma crítica essa elação na sua prática docente.

\section{Ciência, Tecnologia e Sociedade: a importância para a formação do cidadão}

Destacamos novamente a necessidade de se discutir nos Cursos de Licenciatura em Ciências da Natureza (Biologia, Física e Química) a relação entre a Ciência, a Tecnologia e a Sociedade (CTS), de forma que se propicie a formação de cidadãos, pessoas capazes de atuar no mundo de forma crítica e embasada cientificamente. Compreender CTS é também compreender o meio em que se vive e tomar para si a responsabilidade de atuar de forma sustentável num mundo globalizado em constantes modificações tecnológicas e compreender que a Ciência representa uma eterna busca (CHASSOT, 2003). Pensar em trabalhar com o enfoque CTS é pensar em adotar abordagens de ensino que favoreçam a autonomia dos estudantes, corresponsabilizando-os pelo seu próprio aprendizado, além de favorecer a construção de uma visão crítica, reflexiva, 
necessária à tomada de decisão; está fundamentada em argumentos de natureza técnica, científica, social, ética, entre outras, relevantes ao processo educativo. Para formar para a cidadania é necessária à inclusão de discussões sobre questões relacionadas à tríade CTS; pressupõe-se a sensibilização para essas questões inicialmente por meio da formação inicial de professores, uma abordagem temática interdisciplinar é fundamental para contribuirmos para a formação de um pensamento crítico (FAZENDA, 2008).

Assim, acredita-se que para melhoria do processo de ensino e aprendizagem de Ciências na Educação Básica, de forma que este possa ser útil para a formação de cidadãos críticos e atuantes, há que se investir na formação inicial e continuada de professores dentro da perspectiva CTS de Ensino. O Curso de Licenciatura em educação do Campo da UFG/RC busca propiciar uma formação com esta orientação metodológica. Segundo Mortimer e Santos (2002) a existência de um enfoque CTS nas estruturas curriculares das faculdades formadoras dos professores de Química se faz importante, uma vez que a abordagem CTS diferencia e melhora o processo de ensino e aprendizagem e cada vez mais deve estar presente na formação continuada do professor para que este obtenha uma capacitação de qualidade e alcance seu espaço durante o processo de inserção social. Por outro lado, estudos desenvolvidos por Vieira e Martins (2004), ressaltam que se houver investimentos na formação docente para uma abordagem CTS no ensino de Ciências é possível que os futuros professores desenvolvam projetos de ensino de orientação CTS.

Nesta mesma direção encontramos em Acevedo (2002) entendimentos que destacam que a formação docente, quando devidamente orientada, pode contribuir para a (re) elaboração de concepções mais adequadas de Ciência, Tecnologia e Sociedade.

Ainda dentro dessa perspectiva, temos a fala de outros licenciandos, que aos serem questionados sobre sugestões para a melhoria do Ensino e Aprendizagem de Ciências, citam a formação docente na perspectiva CTS como uma das possibilidades para esta melhoria:

Excerto 12 - Formação continuada dentro da perspectiva de ensino CTS para que o ensino se relacione com o cotidiano das pessoas (L9).

Excerto 13 - Uma formação CTS para trabalhar com os futuros educandos (L10).

Pela análise das falas podemos observar que os licenciandos percebem que discutir o Ensino de Ciências dentro que uma perspectiva CTS contribui para o desenvolvimento dos alunos como cidadãos e percebem também a necessidade de que essa discussão também seja mais recorrente nos cursos de formação inicial de professores:

Excerto 14 - Mais formação na área de ensino CTS para relacionar o conhecimento com o cotidiano do aluno (L12). 
Portanto, considera-se que o Curso de Licenciatura em Educação do Campo/UFG/RC tem buscado propiciar uma formação docente crítica, atual e comprometida com a melhoria do Ensino de Ciências na Educação Básica. Prova disto são as disciplinas de Estágio Supervisionado 3 e 4, onde os licenciandos do Curso são chamados a elaborar e aplicar sequencias didáticas centradas na abordagem CTS de Ensino.

\section{Considerações Finais}

Conhecer a Ciência e a Tecnologia e sua relação com a Sociedade é importante para garantir aos sujeitos a capacidade de analisar criticamente as informações, bem como ser crítico frente às decisões políticas, econômicas e socioambientais que regem a nossa sociedade e que atingem diretamente todos os cidadãos. Destarte, vemos na escola um papel fundamental nesse processo, bem como nas Universidades através da formação de professores.

Por meio, dos dados podemos observar que mesmo com a promoção da discussão dos conceitos como de Ciência e cientistas em sua formação através de diversas disciplinas a maioria dos licenciandos pesquisados permanece com uma visão romantizada destes conceitos, ingênua, e de que o objetivo maior da Ciência e da Tecnologia seja o trabalho em prol do bem da humanidade.

Mas mesmo com essa visão romantizada das Ciências podemos observar que os licenciandos têm um indício de um posicionamento crítico e acreditam ser necessário discutir o Ensino de Ciências dentro de uma perspectiva que relacione a Ciência, Tecnologia e Sociedade (CTS), de forma a contribuir com o desenvolvimento dos alunos como cidadão. E mais, percebem a necessidade de que essa discussão também seja mais recorrente nos cursos de formação inicial de professores. Portanto, este artigo permite demonstrar a necessidade da garantia da discussão da abordagem de ensino CTS junto aos licenciandos em sua formação inicial, tanto por meio de disciplinas que discutam teoricamente essa metodologia de ensino quanto através de aulas de conceitos científicos elaborados dentro de tal perspectiva de ensino.

\section{Referências}

ACEVEDO, J. A. Cambiando la práctica docente en la enseñanza de las ciências a través de CTS. Borrador, 13, pp. 26-30 1996.

ADAMS, F. W., ALVES, S. D. A., SANTOS, D. G., NUNES, S. M. T. Contribuições de Aulas Contextualizadas para a Formação Crítico/Reflexiva de Alunos da Educação Básica. REnCiMa, São Paulo/SP, v.7, n.3, p. 01-17, 2016.

AIKENHEAD, G. Consequences to Learning Science Trough STS: A research Perspective. In J. 
Solomon e G. Aikenhead (Eds.). STS Education: International Perspectives on Reform. New York: Teachers College Press, 1994.

AULER, D. Alfabetização científico-tecnológica: um novo “paradigma”? Ensaio - Pesquisa em Educação em Ciências, 5 (1), 1-16, 2003.

AULER, D. Movimento Ciência-Tecnologia-Sociedade (CTS): modalidades, problemas e perspectivas em sua Implementação no ensino de física. Anais... Encontro de Pesquisa em Ensino de Física, 6, Resumos, Florianópolis, 1998.

AVANZI, M. R., GASTAL, M. L., SÁ, S. L., FREITAS, E. L., CANABARRO, P. H. O., LIMA, L. O. B., SOUSA, K. G., ALMEIDA, A. P. C. Concepções sobre a Ciência e os Cientistas entre Estudantes do Ensino Médio do Distrito Federal. Anais... do VIII Encontro Nacional de Pesquisa em Educação em Ciências - ENPEC, 2011. Resumos eletrônicos. Disponível em: http://www.nutes.ufrj.br/abrapec/viiienpec/resumos/R1113-2.pdf; Acesso em 02 fev. 2019.

CACHAPUZ, A. F. Tecnociência, poder e democracia. In: SANTOS, Wildson Luiz Pereira dos; AULER, Décio (Orgs.). CTS e Educação Científica: desafios, tendências e resultados de pesquisas. Brasília: Editora Universidade de Brasília, 2011.

CHASSOT, A. Alfabetização Científica: questões e desafios para a educação. Зe. Ijuí: Unijuí, 2003.

A ciência é masculina? É, sim senhora! 7a ed.. Ijuí: Unisinos. 2015.

DELIZOICOV, D., ANGOTTI, J. A., PERNAMBUCO, M. M. Ensino de Ciências: fundamentos e métodos. 3. ed. São Paulo: Cortez, 2009.

DUARTE, D. P., PARENTE, A. G. L. O pensar e o fazer docente no clube de ciências da UFPA: Reflexões sobre a prática. Amazônia. v. 2, n. 3. 2005/ v. 2, n. 4, 2006.

FAZENDA, I. O Que é interdisciplinaridade? São Paulo: Cortez, 2008.

FENSHAM, P. School science and public understanding of science. International Journal of Science Education, v. 21, n. 7, p. 755-63, 1999.

FREIRE, P. Pedagogia da autonomia: saberes necessários à prática educativa. São Paulo: Paz e Terra, 1996.

GATTI, S. R. T., NARDI, R., S, D. História da ciência no ensino de física: um estudo sobre o ensino de atração gravitacional desenvolvido com futuros professores. Investigações em Ensino de Ciências, 15(1), 7-59, 2010.

GIL, A. C. Métodos e técnicas de pesquisa social. 5 ed. São Paulo: Atlas, 1999.

GIL-PÉREZ, D., MONTORO I. F., ALÍS, J. C., CACHAPUZ, A., PRAIA, J. Por uma imagem não deformada do trabalho científico. Ciência \& Educação, v.7, n.2, p.125-153, 2001.

GONÇALVEZ, C. A. N., SIQUEIRA BATISTA., R. Ensino de Ciências: Dialogando com David Ausubel. Revista Ciências\&Ideias, n1, volume 1- outubro/ março, p. 23-31, 2010.

HOFSTEIN, A., AIKENHEAD, G., RIQUARTS, K. Discussions over STS at the fourth IOSTE symposium. International Journal of Science Education, v. 10, n. 4, p.357-366, 1988.

KOSMINSKY, L., GIORDAN, M. A visão de ciências e sobre cientista entre estudantes do ensino médio. Química Nova na Escola. n. 15, p. 11-18, 2002.

LINCOLN, Y. S., GUBA, E. G. Naturalistic inquiry. 1. ed. London: Sage, 1985. 
LINSINGEN, I. V. Perspectiva educacional CTS: aspectos de um campo em consolidação na América Latina. Ciência \& Ensino, (número especial), 2007.

LÓPEZ, J. L. L., CEREZO, J. A. L. Educación CTS en acción: enseñanza secundaria y universidad. In: GARCÍA, M. I. G., CEREZO, J. A. L., LÓPEZ, J. L. L. Ciencia, tecnología y sociedad: una introducción al estudio social de la ciencia y la tecnología. Madrid: Editorial Tecnos S. A., 1996.

LUDKE, M., ANDRÉ, M. E. D. A. Pesquisa em educação: abordagens qualitativas. São Paulo: EPU, 1986.

MAGALHÃES, S. I. R., TENREIRO-VIEIRA, C. Educação em Ciências para uma articulação Ciência, Tecnologia, Sociedade e Pensamento crítico. Um programa de formação de professores. Revista Portuguesa de Educação, nº 19, volume 2, pp. 85-110, 2006.

MARCONI. M. A., LAKATOS, E. M. Fundamentos de metodologia científica. São Paulo: Atlas, 2010.

MARTINS, I., PAIXÃO, F., VIEIRA, R. (Org) Perspectivas Ciência-Tecnologia-Sociedade na Inovação da Educação em Ciência. Aveiro: Universidade de Aveiro, 2004.

MARTINS, H. H. T. D. Metodologia qualitativa de pesquisa. Educação e Pesquisa, São Paulo, v.30, n.2, p. 289-300, maio/ago. 2004.

MORAES, R.; GALIAZZI, M. C. Análise Textual Discursiva. Ijuí/RS: Editora Unijuí, 2007

MORAES, R.; GALIAZZI, M. C. Análise textual discursiva. 3 ed. Revisada e Ampliada. Ijuí: Unijuí, 2016.

MORAES, R., GALIAZZI, M. C. Análise textual discursiva: processo construído de múltiplas faces. Ciência \& Educação, v.12, n.1, p.117-128, 2006.

MORTIMER, E. F., SANTOS, W. L. P. Uma análise de pressupostos teóricos da abordagem CTS (Ciência -Tecnologia -Sociedade) no contexto da educação brasileira. Ensaio, Pesquisa em Educação em Ciências. Vol., $\mathrm{n}^{\mathrm{o}}$ 1(set) 1999. Disponível em: https://periodicos.ufmg.br/index.php/ensaio/issue/archive. Acesso em: 02 de fevereiro de 2019.

NUNES, S. M. T., RETONDO, C. G., EPOGLOU, A., TEIXEIRA JUNIOR, J. G. O Ensino CTS em Educação Química: Uma Oficina Para Professores e Alunos do Curso de Licenciatura em Química da UFG. Poiésis Pedagógica, v. 7, p. 93-108, 2009.

REIS, P., GALVÃO, C. O diagnóstico de concepções sobre os cientistas através da análise e discussão de histórias de ficção científica redigidas pelos alunos. Revista Electrónica de Enseñanza de las Ciencias, v.5, n.2, p.213-234, 2006.

REZNIK, G., MASSARANI, L., RAMALHO, M., AMORIN, L. Ciência na televisão: Uma análise do telejornal Repórter Brasil. Alexandria Revista de Educação em Ciência e Tecnologia, v. 7, n.1, p. 157-178. 2014.

SÁ, J. Renovar as Práticas no $1^{\circ}$ Ciclo Pela Via das Ciências da Natureza. 2 ed. Porto: Porto Editora, 2002.

SANTOS, W. L. P. Contextualização no ensino de ciências por meio de temas CTS em uma perspectiva crítica. Ciência \& Ensino, vol. 1, número especial, p. 1 - 12, novembro de 2007.

SANTOS, W. L. P., SCHNETZLER, R. P. Educação em Química: compromisso com a cidadania. Ijuí: Unijuí, 2000.

SANTOS, W. L. P., AULER, D. (organizadores). CTS e educação científica: desafios, tendências e 
resultados de pesquisas. Brasília: Editora Universidade de Brasília, 2011.

SIRGADO, A. O social e o cultural na obra de Vigotski. Educação \& Sociedade. n.71, p. 45-78, 2000.

TEIXEIRA, P. M. M. A educação científica sob a perspectiva da pedagogia histórico-crítica e do movimento C.T.S. no ensino de ciências. Ciência \& Educação, v. 9, n. 2, p. 177-190, 2003.

TOMAZI, A. L., PEREIRA, A. J., SCHÜLER, C. M., PISKE, K., TOMIO, D. O que é e quem faz ciência? Imagens sobre a atividade científica divulgadas em filmes de R. Bras. Ens. Ci. Tecnol., Ponta Grossa, v. 9, n. 3, p. 1-23, mai./ago. 2016. Ensaio - Pesquisa em Educação em Ciências. v.11, n.2. 2009.

VIGOTSKI, L. S. A construção do pensamento e da linguagem. Tradução de Paulo Bezerra. São Paulo: Martins Fontes, 2001.

VIEIRA, R. M., MARTINS, I. P. Impacto de um programa de formação com uma orientação CTS/PC nas concepções e práticas de professores. In I. P. MARTINS; F. PAIXÃO \& R. M. VIEIRA. Perspectivas Ciência-Tecnologia-Sociedade na Inovação da Educação em Ciência. (pp. 47-55) Aveiro: Universidade de Aveiro, 2004.

ZAGO, N. et al. (Org.). Itinerários de Pesquisa - perspectivas qualitativas em Sociologia da Educação. Rio de Janeiro: DP\&A, 2003.

Recebido em: 07/12/2019

Aprovado em: 28/04/2020 